\title{
Por uma psicologia não moderna: o PesquisarCOM como prática meso-politica
}

\section{For a non modern psychology: the ResearchWITH as a mesopolitical practice}

\section{Por una Psicologia no moderna: el investigarCOM como práctica meso-política}

\section{Ronald Arendt*}

Universidade do Estado do Rio de Janeiro - UERJ, Rio de Janeiro, Rio de Janeiro, Brasil

\section{Marcia Moraes**}

Universidade Federal Fluminense - UFF, Niterói, Rio de Janeiro, Brasil

\section{Alexandra Tsallis***}

Universidade do Estado do Rio de Janeiro - UERJ, Rio de Janeiro, Rio de Janeiro, Brasil

\begin{abstract}
RESUMO
O objetivo deste artigo é investigar possíveis contribuições da filósofa belga I sabelle Stengers para a construção do pesquisarCOM, um modo de fazer psicologia proposto por Moraes (2010). Partindo-se das noções de subjetividade e meso-política, afirmadas pela filósofa, o artigo indica que uma psicologia não moderna se torna possível se compreendermos 0 dispositivo de pesquisa não como um arranjo, que separa sujeito e objeto, mas como uma prática que não cessa de agenciar elementos heterogêneos. Investindo na meso-política, como uma política de vínculos, o artigo assevera que o pesquisarCOM é uma prática meso-política. FazerCOM o outro a pesquisa em psicologia é um modo de pôr em cena uma psicologia não moderna, isto é, uma psicologia cujas práticas passam ao largo das clássicas separações entre sujeito e objeto, pesquisador e pesquisado. $\mathrm{O}$ artigo conclui com um exemplo de uma Oficina de Experimentação Corporal com pessoas cegas e com baixa visão, inscritos numa instituição de reabilitação para pessoas com deficiência visual, insistindo que pesquisar é transformar-se no encontro com o outro, é fazer proliferar um mundo mais denso, que não estava dado de antemão, um mundo inantecipável, tecido de elementos heterogêneos, díspares, humanos, não humanos, ciborgues.
\end{abstract}

Palavras-chave: subjetividade, meso-política, pesquisarCOM.

\section{ABSTRACT}

The aim of this paper is to investigate possible contributions of philosopher I sabelle Stengers for the construction of the researchWITH, a way of doing psychology proposed by Moraes (2010). Based on the notions of subjectivity 
and meso-politics, affirmed by the Belgian philosopher, the paper indicates that a non- modern psychology becomes possible if we affirm the research device not as a modern arrangement, which separates subject and object, but as a practice that does not cease of assembling heterogeneous elements. Investing in meso - politics as ties politics, the paper states that the researchWITH is a meso - political practice. Do psychology research WITH the other is a way to stage a non- modern psychology, that is, a psychology whose practices are off the classic separation between subject and object, researcher and researched. The article concludes with an example of an experimental body workshop with blind people inscribed in a visual rehabilitation institution for people with visual impairment insisting that research is becoming with the encounter with the other, spawning a denser world, which was not given beforehand, one unpredictable world, made by heterogeneous elements, disparate, human, non-human, cyborgs.

Keywords: subjectivity, mesopolitic, researchWITH.

\section{RESÚMEN}

El objetivo de este trabajo es investigar la posible contribución de la filósofa Isabelle Stengers para la construcción del investigarCOM, una forma de hacer psicología propuesto por Moraes (2010). Sobre la base de las nociones de subjetividad y meso-política, propuestas por la filósofa belga, el artículo indica que una psicología no moderna es posible cuando afirmamos el dispositivo de investigación, no como un arreglo moderno, que separa sujeto y objeto, sino como una práctica que no deja de hacer cesar la adquisición de elementos heterogéneos. Invirtiendo en la meso-política como una política de los lazos, el artículo establece que el investigarCOM es una práctica meso-político. HacerCOM el otro las investigaciones en psicología es una manera de hacer una psicología no moderna, es decir, una psicología cuyas prácticas están fuera de la clásica separación entre sujeto y objeto, investigador e investigado. El artículo concluye con un ejemplo de una Oficina de Experimentación Corporal con personas ciegas y con baja visión, inscritas en un centro de rehabilitación para las personas con discapacidades visuales, insistiendo que la afirmación de que la búsqueda se está convirtiendo en el encuentro con el otro, generando un mundo más denso, que no estava dado de antemano, un mundo imprevisto, tejido de elementos heterogéneos, dispares, humanos, no humanos, cyborgs.

Palabras clave: subjetividade, meso-política, investigarCOM.

\section{Introdução}

Na seção de agradecimentos do seu último livro "Recherches sur les Modes d' existence", Bruno Latour (2012) faz uma bela homenagem à filosofa belga Isabelle Stengers por ela ter lido, corrigido e criticado as sucessivas versões do seu livro. Foi por isso que ele propôs beneficiar-se do slogan dos chips da Intel e declarar seu selo de qualidade: "IS inside", fazendo menção às iniciais do nome da filósofa. (Latour, 2012, p. 9) ${ }^{1}$. É antiga a colaboração de Stengers com a teoria do ator-rede: ainda segundo Latour (2004), ela teria, com Vinciane Despret, elaborando o que para ele seria uma "epistemologia política normativa alternativa" (Latour, 2004, p. 214). Por se tratar de um número dedicado à teoria do ator-rede optamos 
por apresentar um ensaio que aprofundasse algumas linhas do pensamento da filósofa belga, particularmente no que tange à sua influência no desenvolvimento de uma psicologia não moderna, inspirada nas contribuições da teoria ator-rede.

Neste ensaio vamos nos deter em algumas obras da filósofa, na expectativa de que com elas possamos levar adiante o que em outros trabalhos temos chamado de psicologia não moderna (Arendt, 2008; Ferreira, Luna, Moraes, \& Arendt, 2010; Ferreira, 2011). Nas linhas a seguir, partimos da concepção de subjetividade defendida por Stengers num artigo publicado na revista inglesa "Subjectivity" (Stengers, 2008) que, no nosso entender, pode se vincular a um conceito novo que emerge em entrevistas recentes concedidas em 2009 e 2012, nas quais a filósofa introduz a noção de uma "meso" política, situada entre a "macro" e a "micro" políticas. Ao final de nosso ensaio procuraremos associar a referida meso-política ao pesquisarCOM, tal como proposto por Moraes (2010). Afirmamos que pesquisarCOM é uma prática meso-política, um modo de fazer a psicologia que põe em cena a hesitação e o mal entendido promissor como vetores de aprendizagem coletiva que envolvem todos os participantes do dispositivo de pesquisa, sejam eles pesquisadores ou pesquisados. Desta feita, o artigo faz a proposição de uma psicologia não moderna (Arendt, 2008) lançando mão de articulações com as contribuições de Isabelle Stengers (2012, 2009, 2008, 2006, 2002a) na discussão do pesquisarCOM.

\section{Subjetividade e a questão ecológica: pensar pelo meio}

No artigo a que nos referimos acima (Stengers, 2008) a filósofa belga inicia seu texto dizendo que a escolha deste termo pela revista obviamente não se referiria a uma estrutura dualista moderna em oposição à objetividade, mas provavelmente àquilo que genericamente chamaríamos de "eventos de produção de subjetividade", quando, nas práticas sociais o que foi silenciado encontra sua própria voz, produz seu próprio ponto de vista, seus próprios meios de resistir a um consenso moral ou à definição estabelecida do que deveria ser tomado em consideração. Entretanto, deveríamos resistir à tentação de considerar que através de tais eventos escaparíamos ao que ela (2002a) e Latour (1994, 2012) chamam de "território moderno", regido pela oposição entre objetividade e subjetividade. Trata-se de caracterizar este território como um processo de captura e abordar a possibilidade de fabricar linhas de fuga para escapar deste território, no qual estamos todos envolvidos. O objetivo de Stengers $(2008,2006)$ não seria tanto o de denunciar o território moderno, mas, ao tornar perceptíveis seus poderes, suas forças, traí-lo, numa busca de encontros e conexões 
que suscitem novas discriminações, antes de estabelecer critérios de julgamento.

Stengers (2008) dá um exemplo, colhido da tese de PhD de Maria Puig de La Bellacasa, defendida em 2004 e publicada em livro em 2012 (Bellacasa, 2012). As feministas americanas tiveram que aprender de suas irmãs afro-americanas 0 quanto eram perigosamente parciais suas concepções de "mulher".

"A produção de uma posição subjetiva divergente desfazia a possibilidade de um simples "nós" e as consequências deste evento estão ainda num processo que demanda um desdobramento difícil e hesitante - veja-se também o dilema das feministas francesas face à produção de subjetividade demonstrada pelas novas (novas em termos de sua juventude e sua política) mulheres muçulmanas veladas" (Stengers, 2008, p. 41).

Este desdobramento nos solicita na medida em que seu objetivo é que continuemos a aprender a partir das consequências de qualquer definição, fazendo-nos hesitar sobre as nossas próprias condições de pensamento.

O que seria então trair o território moderno e fabricar linhas de fuga? Seria descobrir ingredientes que pertencessem ao mesmo tempo ao território e que se conectassem com forças contra as quais ele seria levado a se proteger. Stengers (2008) dirá que estes ingredientes produzem discriminações, produzem

o que Deleuze celebrou quando comparou a ética de Spinoza a uma etologia, um tratado de bons e maus encontros: não sobre o que poderia ser bom ou mal em si, mas sobre aprender como o que encontramos nos afeta, como nos dá forças ou nos afasta de nossa capacidade de agir (isto é, também de pensar e sentir). Forças então são assunto de uma 'etologia crítica'. Nenhuma força é boa ou ruim. É o agenciamento ${ }^{2}$ que passa a existir quando encontramos uma força e somos afetados por ela e que solicita experimentação e discriminação, pois capturar uma força, ser modificado por ela, "forçado" a pensar, sentir e ter experiência nunca é sem perigo (p.44).

A subjetividade deve se apresentar então como um ingrediente do agenciamento e não algo a ser desmembrado e criticamente examinado. Retomando a observação de William James sobre o medo, na qual é difícil decidir se este foi devido a algo assustador ou foi percebido como assustador devido a nosso medo, Stengers (2008) dirá que o ponto não é dirigir-se à indecisão, mas habitar a situação não decidida e aprender com o que ela demanda. Apoiando-se ainda 
em Deleuze, ela sugere que a situação tem a ver com uma "dramatização" - na qual nos dirigimos a cada situação como um evento que solicita suas próprias questões. A questão poderia ser então "que tipo de atenção, preocupação e cuidado são necessários" nesta situação? "Discriminação" envolve então a capacidade de aprender. Tradições não-modernas, por exemplo, podem ter habitado esta questão de outra maneira, transformando os perigos do território moderno num envolvimento pragmático. Elas sabem que o encontro com as "forças" necessita cuidado: encorajar e alimentar agenciamentos será então uma questão relacional situada.

Quando se trata de "re-priorizar a subjetividade" esta discriminação poderá pedir que nos abstenhamos de celebrar a produção de subjetividade dos eventos enquanto justificada por seu poder de disrupção, rompendo o status quo consensual, repressivo. Aprender significa conexão com tais eventos. Aprendemos quando de fato conectamos e somos testados pela conexão. O que esta conexão está nos solicitando? Por exemplo, está ela solicitando uma traição, tornando possível a possibilidade de um salto que podemos ou devemos efetuar? (Stengers, 2008, p. 45)

Stengers (2008) está falando a partir de William James que dramatizou o "encontro com uma força" como um salto que pede confiança, mas não oferece garantia. Trata-se da confiança na possibilidade de que alguma coisa venha e faça conexão. É interessante notar o modo como a autora lança mão destes argumentos justamente para colocar em questão aquilo que ficou conhecido como "a guerra das ciências", isto é, o debate que envolveu denúncias reciprocas, entre de um lado, cientistas sociais e de outro, os cientistas naturais. Para estes últimos, a "Natureza fala" e esta fala é objetiva e isenta de qualquer reflexividade humana. Já para os primeiros, a ciência não seria mais do que uma prática humana, entre outras. A análise apresentada por Stengers (2008) para este debate moderno que opõe Natureza e Sociedade é tecida levando às últimas consequências o argumento de James: que alguma coisa venha e faça conexão - isso não pode jamais ser reduzido a uma questão geral.

O problema da critica dos cientistas sociais à afirmação de que a "Natureza fala" é que ela se apresenta como uma contraposição àquela dos cientistas naturais, ficando, pois inserida no território moderno. Stengers $(2008,2006)$ afirma uma outra forma de tratar da questão quando propõe suprimir o adjetivo "humanas" como algo que qualifica as práticas científicas. Tal supressão torna possível vislumbrar a especificidade das práticas experimentais entre outras 
práticas as quais, elas também, não podem ser caracterizadas como apenas humanas, uma vez que

(...) a prática designa as ciências 'se fazendo', ela engloba o ajuste de instrumentos, a escritura de artigos, as relações de cada praticante com os colegas, mas também com tudo isto que e todos aqueles que contam ou poderiam contar em sua paisagem. Nada está pronto. Tudo está por negociar, por ajustar, alinhar e o termo prática designa a maneira pela qual tais negociações, ajustes, alinhamentos constringem e especificam as atividades individuais sem por isso determinálas. (Stengers, 2006, p. 62-3).

Mais uma vez insistindo no caráter local e situado das conexões que fazem com que alguma coisa venha a existir, Stengers (2008) levanta questões interessantes, que dizem respeito àqueles envolvidos nas práticas: "o que os situa, o que os força a pensar e sentir e hesitar de um modo que os marca como pertencendo a esta prática, ciência experimental?".

A afirmação de que a Natureza fala não é, para a filósofa, uma afirmação de autoridade, mas, antes, uma proposição Jamesiana. "Alguma coisa encontrou o salto do cientista, uma conexão foi produzida, fatos foram produzidos, os quais são dotados com um raro poder de impor de modo confiável como eles deveriam ser interpretados" (Stengers, 2008, pag. 47). O que força o cientista a pensar, sentir e hesitar é antes, o resultado de um processo que pouco tem a ver com a moderna oposição entre subjetividade e objetividade. É antes, um evento: o chegar a existir de alguma coisa que tem o poder de produzir um acordo entre os cientistas que partilham uma mesma paixão investigativa, que os leva a conceder valor àquilo que força o acordo entre eles. Trata-se, pois, de uma arte, uma aprendizagem: a discriminação. Por esta via, faz-se mister considerar que a separação entre o subjetivo, como aquilo que decorre apenas da nossa interpretação, e o objetivo, aquilo que decorre exclusivamente do mundo lá fora, não tem nada de geral, de desencarnada. É uma questão local, performativa, situada. Nas palavras da autora:

É antes a perfomatividade ${ }^{3}$ de uma subjetividade peculiar produzida através de, e demandada por, tornar-se parte de uma fábrica muito específica de ciência experimental, uma fábrica que pressupõe e proclama uma versão específica da confiança precursiva jamesiana: pode acontecer que a demanda seja alcançada por fatos que forçam acordo (Stengers, 2008, p. 47). 
A questão de Stengers (2008) neste ponto não é, de modo nenhum, reforçar a Ciência, com $\mathrm{C}$ maiúsculo, mas de alguma maneira abrir a possibilidade de conexão com aqueles cientistas que lutam contra a autoridade excessiva do argumento da objetividade, sem no entanto, se inserirem na falácia irônica de afirmar que "isso não passa de uma construção humana". Se esta possibilidade de conexão é aberta, novas formas de resistência podem se constituir em oposição à arrogância da extensão dos critérios de cientificidade como se eles fossem normas gerais e não tecidas e performadas nas práticas experimentais. O ponto aqui é precisamente fabricar a linha de fuga frente à escolha binária entre objetividade e subjetividade. Desta feita, na afirmação pragmática de Stengers $(2008,2006)$, o que nós chamamos de cientista não pode ser desvinculado ou abstraído da questão ecológica, a questão do meio, de um meio que aceita e propaga um tipo de generalização grandiosa da objetividade como norma geral relacionada a uma teoria geral do conhecimento. A afirmação da noção de prática, tal como proposta pela autora, é um gesto que simultaneamente, afirma a fabricação de uma linha de fuga frente às escolhas binárias da modernidade e defende o caráter performativo, local, situado do conhecimento. A questão ecológica é uma questão de encontros, de conexões e não de determinações dualistas. Que política e que conhecimento advém deste modo de situar e colocar as práticas científicas?

Pensar pelo meio, pela questão ecológica, não significa que a objetividade, a Natureza lá fora, determina e garante o conhecimento. Nem tampouco que a subjetividade impõe seus matizes interpretativos ao mundo. Pensar pelo meio significa que 0 conhecimento se faz no enredamento, na conexão, no engajamento. É por isso que a filósofa pode levantar a questão acerca do que seriam os cientistas, e a ciência, em meios diferentes, com outras conexões, outros interlocutores além do Estado, da Indústria, do raciocínio em termos dedutivos, etc. Levando ainda mais longe esta interrogação, a autora coloca em questão o meio em que ela, enquanto filósofa, está inserida: o meio acadêmico. O que seria de nós se não nos constituíssemos num meio que separa "nós" - os cientistas, os intelectuais - e eles, os outros, os pesquisados, os objetos? O que seria do nosso meio se pudéssemos nos constituir longe da dicotomia "nós-sabemos" X "eles-não-sabem"? São estas as questões que nos abrem para a meso-politica.

\section{A meso-política}

Em duas importantes entrevistas, Stengers $(2009,2012)$ introduz a noção de meso-política. A questão meso, diz Stengers, começa numa política de vínculos. "O sucesso típico de um dispositivo meso poderia 
ser conferir a uma situação o poder de fazer pensar juntos aqueles que estão a ela vinculados de maneira a priori conflituosa" (Stengers, 2009 , p. 5). Não se trata, porém, de um ideal a ser atingido: não se copiam vínculos, não há uma boa vontade em colaborar, não se simulam vínculos. O que importa é a confiança num evento "pelo qual uma situação pode fazer pensar aqueles que ela concerne, pode escapar ao destino comum que é de ser definida por termos preexistentes" e assim "adquirir o poder de situar aqueles que ela reúne e isto sem que haja uma conversão a um consenso unânime" (Stengers, 2009, p. 05). As ciências podem ser um exemplo desta situação, observa Stengers (2008), elas "não são um modelo, elas são um exemplo muito particular da produção de subjetividade que se produz quando uma situação... força a pensar, a imaginar, a criar aqueles que ela reúne" (Stengers, 2009, p. 06).

A questão política dos vínculos pode ser aventada ainda no nível químico e biológico. Comparando o nível molecular ( $p$. ex. uma molécula de água) com o nível molar ( $p$. ex. uma molécula biológica), Stengers (2009) dirá que esta última, ao contrário da primeira, implica em interações que permitem "tornar perceptível a necessidade de uma eto-ecologia, onde o ethos da molécula, aquilo que ela é capaz, não pode ser dissociado de seu oikos, do meio que requer este ethos" (p. 03). A física, no nível micro, nós a conhecemos bem, ela "é o que os físicos sonham e fazem sonhar, o macro é o familiar, são os cristais, os líquidos, os corpos que podemos caracterizar pelas propriedades gerais, mensuráveis. O 'meso' não é nenhum, nem outro, o 'meso' concerne não tanto à matéria e mais ao material" (Stengers, 2009, p.04). Na entrevista de 2012 a autora refina esta análise explicando que físicos, segue ela, aprendem que há micro-física (átomos, moléculas) e macro-física (temperatura, coisas que você pode medir), porém a escala dos materiais é sempre meso. Materiais não são abstratos como um cristal perfeito ou um puro gás, que são caracterizados por escalas bem definidas. Quando você tem um puro cristal ele pode ser compreendido em termos micro ou macro. Mas logo que você tenha algo que pode ser flexionado, ou quaisquer propriedades de materiais como resistência, fadiga, plasticidade, elasticidade, limites de elasticidade, você não pode compreendê-las em termos macro ou micro. Tais propriedades exigem a introdução de uma escala meso, uma escala que não é fixa porque ela permite caracterizar interstícios, defeitos, erros e suas consequências (Stengers, 2012, p. 09). Se as propriedades da matéria podem ser derivadas de generalidades, o meso reativa maravilhosamente os procedimentos de fabricação. "Martelar, mergulhar a espada na água fria, todo o tato do metalúrgico, seu golpe de vista, não têm sentido nem micro nem macro." (Stengers, 2009, p. 04). 
Trazendo sua terminologia para a política, Stengers (2009) dirá que você não pode comandar tensões micro-políticas, mas você pode saber que suas consequências vão depender parcialmente da maneira como você irá lidar com elas. Um belo exemplo nos é dado por John Law (2004), em seu livro After Method, relata um trabalho de campo efetuado por Marianne de Laet e Annemarie Mol, no Zimbabwe. O governo havia repassado aos habitantes dos vilarejos espalhados pelo país a responsabilidade de instalar e manter uma determinada bomba de água. Ao sair da manufatura todas as bombas eram iguais. Longe da sede do fabricante, surge o problema: o que fazer quando, em cada vilarejo, as peças quebravam, ficavam velhas e precisavam ser substituídas? Em cada situação ocorria um fazer local que surpreendia até mesmo o inventor da bomba, pelas inovações introduzidas pelos aldeões para manter suas bombas funcionando. Impressiona, neste exemplo, a recepção não uniforme do objeto pelas diferentes coletividades, o conjunto de práticas heterogêneas concomitantes e processuais que, em cada coletivo, fizeram fazer ${ }^{4}$ os atores, e os obrigaram a inventar dispositivos para que o problema de ter água pura pudesse ser resolvido localmente.

Mol e Laet (apud Law, 2004), entretanto, não relatam os casos nos quais os dispositivos não funcionaram, nos quais o dispositivo inventado falhou e o vilarejo se viu sem água pura para sobreviver. Aí reside um aspecto perturbador da meso-política: as ações coletivas podem resultar em adicionar algo que nunca aconteceu e abrir novos tipos de possibilidades, mas podem também ser destrutivas ao falhar, um pouco como ocorre no que tange às propriedades do material, do metal que cansa e depois quebra.

Não é o caso de dizer o que é bom para o grupo, mas como um novo ingrediente foi acrescentado às suas preocupações e às suas relações com outros. Num grupo, não se trata de atingir um esquema universal de liberação, isto equivaleria ao ideal do cristal, trata-se de interessar os membros pela maneira como as respostas são dadas e da sua percepção que o projeto depende de sua compreensão. Este interesse criará um nível meso fazendo possíveis novas relações entre eles, produzindo novos graus de liberdade. "Meso é sobre fazer novas possibilidades pensáveis", diz Stengers (2012, p.10). Como no exemplo das bombas de água do Zimbabwe, em um nível meso tratase de "cuidar de micro eventos, a maneira como eles se dobram, com suas consequências" (Stengers, 2012, p. 10). A meso-política se funda na experiência de um processo de aprendizagem coletivo em que todos hesitam juntos. O nível meso é transformador, "é quando a fabricação (craft) ou a arte do agenciar pode ser desenvolvida. Esta arte não será nunca uma teoria ou uma ciência, mas uma experiência que pode ser destruída por uma antecipação idealística seguida por triste desapontamento." (Stengers, 2012, p. 11). 
É por isso que Stengers (2009) dirá que a meso-política "é a ciência dos interstícios e das falhas. É a ciência dos defeitos" (p. 04). Para melhor compreendermos esta afirmação, vamos por partes. No que tange aos defeitos e falhas retornemos brevemente ao conceito de mal-entendido promissor proposto por Vinciane Despret (1999). Este 'mal-entendido' está sempre vinculado ao dispositivo do pesquisador de campo que, ao se deparar com um dado inesperado, incongruente, estranho, ao invés de expurgá-lo e seguir adiante em seu design de pesquisa se deixa surpreender pelo dado, reavalia este design, e faz de uma falha, de um desapontamento, de um defeito de avaliação ou análise uma possibilidade de um desvio de trajeto. A falha, o defeito, neste sentido, para o pesquisador atento e sensível, é um alerta de que algo precisa ser redimensionado, abrindo a possibilidade de outros trajetos que modificarão o projeto original. Stengers (2009, 2012) se funda aqui na obra do filósofo francês Etienne Souriau (2009) que analisou detalhadamente como age um artista, como ele instaura sua obra, como ele é responsável por levá-la até o fim, com o risco de falhar durante o seu trajeto ${ }^{5}$. Afirma a filósofa belga:

Gosto da noção de instauração de Etienne Souriau porque, a propósito do artista no trabalho, ela desdobra um agenciamento bastante fabuloso que retira toda potência ao velho conflito entre determinação e liberdade. ... Se uma obra de arte pode falhar, questão prática, outras questões se colocam. A questão do sucesso ou insucesso é eminentemente política. Ela é meso, porque não se trata de sucesso no sentido sociológico, macro, e ela requer certamente o micro, mas não é seu problema. O contraste sucesso/insucesso coloca questões diferentes, pragmáticas, em relação experimental com os meios (Stengers, 2009, p. 04).

E os interstícios? Stengers $(2009,2012)$ inspira-se aqui no filósofo inglês Alfred North Whitehead ${ }^{6}$. Whitehead (apud Stengers, 2002b) é o filósofo da criação e das possibilidades de solução, o filósofo que procurou pensar o novo, o risco, a aventura, do salto sem garantias de James; ele é também o filósofo do movimento, da mudança, do processo. Como colocar isto em poucas palavras? Iniciemos com o conceito de natureza. Para Whitehead (apud Stengers, 2002b) "a natureza é aquilo que temos a experiência na percepção" (Stengers, 2002b, p. 45). Logo adiante, outra frase: "Somos instintivamente levados a crer que, se a ela dirigirmos a atenção que convém, encontraremos mais na natureza do que observamos num primeiro golpe de vista. Mas não aceitaremos encontrar menos" (Stengers, 2002b, p. 51).

Algumas conclusões podem ser tiradas destas afirmações. Não há um mundo lá e nós aqui. Estamos inseridos neste mundo e o percebemos 
a partir de um ponto de vista particular. Se ampliarmos este ponto de vista, se olharmos para o mundo com mais atenção, encontraremos mais do que observamos anteriormente. O tempo passa, nós nos transformamos pela multiplicidade da natureza que nos afeta. Nunca esgotamos numa percepção a riqueza desta natureza, é sempre possível surpreendermo-nos com mais percepções, se a devida atenção for exercida. O novo é este mais que constituirá outra concepção da natureza (do mundo) a partir da multiplicidade de percepções possíveis, combinando, conectando, criando o que não havia antes. Whitehead (apud Stengers, 2002b) tem uma concepção precisa do social: social é tudo que de alguma maneira está constituído num sistema de relações (num nível macro). O autor utiliza uma bela metáfora para caracterizar este social: imagine-se um muro, feito de tijolos, este muro seria o social. Imagine-se, porém que entre os tijolos vicejem, trazidas pelas sementes que pássaros ou morcegos deixaram, pequenas ervas. Estas irão deslocar os tijolos. É curioso que estes interstícios dependem do social, emergem a partir do social e o deslocam, mas não são de saída, sociais. Stengers $(2012,2002 b)$, a partir de Whitehead, irá então propor uma cultura dos interstícios. Estes interstícios são o intermediário entre o muro e os pássaros que trazem as sementes, a grama que vai crescer (num nível micro). As transformações, as mudanças, o deslocamento, as novas percepções, as negociações entre os novos elementos se darão num nível, meso. Assim, no decorrer desta argumentação foi possível indicar como através das falhas e dos interstícios das práticas uma situação faz pensar juntos aqueles que estão a ela vinculados de maneira a priori conflituosa e como através delas esta situação faz "pensar aqueles que ela concerne", propiciando que eles escapem ao "destino comum de serem definidos por termos preexistentes" e assim "adquirir o poder de situar aqueles que ela reúne e isto sem que haja uma conversão a um consenso unânime".

\section{PesquisarCOM e a meso-política}

Nas histórias orais que se contam na Grécia, uma delas nos interessa porque toca no ponto chave do nosso argumento. Na Atenas de Pericles (século IV a.C.) foi construído na Acrópolis o Parthenon, templo dedicado a Palas Atena. A deusa da sabedoria, da diplomacia, da guerra, da tecelagem, aquela que foi parida após uma martelada dada por Hefesto na cabeça de Zeus que estava com uma imensa dor de cabeça. Ela já nasceu pronta, adulta e com o casco na cabeça, mas vale a pena relatar uma interessante história que é contada sobre a estátua de Palas Atena que foi feita para ocupar o centro do templo. 
Quando o Parthenon estava praticamente pronto houve um concurso para escolher qual seria a estátua de Palas Atena que ocuparia o alto pedestal. Participaram fazendo propostas vários artistas da época, entre eles, estava concorrendo, Fidias - o próprio arquiteto do Parthenon. Todos os concorrentes apresentaram suas maquetes aos jurados. Qual foi a surpresa de todos quando viram a maquete proposta por Fídias: ela era estranha, suas formas não guardavam as proporções de um corpo humano. Não havia dúvida de que os jurados deveriam escolher uma bela estátua e não uma Palas Atena esquisita. Pairava no ar a pergunta: como podia ser que logo Fidias, o brilhante arquiteto, trouxesse uma proposta tão descabida. Porém, antes que se definisse o resultado do concurso, Fidias fez um pedido ao júri: solicitou que sua maquete não fosse julgada dessa forma, ele pediu que ela fosse colocada sobre o pedestal construído e só então se definisse o resultado. $O$ pedido foi considerado procedente pelo júri e isso foi feito. Qual foi a surpresa de todos quando viram a beleza de Palas Atena sobre o pedestal. Ela já não era desproporcional, pelo contrário, suas formas guardavam a justa proporção dos corpos humanos. Já não havia dúvida de que a estátua de Fidias era aquela que deveria estar no centro do templo. E lá ficou a deusa por muitos anos. Infelizmente, hoje a estátua não existe mais, porém sua história ainda é contada para aqueles que visitam o Parthenon.

O que Fidias havia levado em conta para fazer sua estátua? Fidias havia levado em conta o ponto de vista. Ele percebeu que as formas humanas da estátua precisariam se articular aos corpos daqueles que para ela olhariam. As pessoas estariam lá-embaixo e Palas Atena estaria lá-em cima, mas entre elas estava o meio ou como diriam os gregos estava o meso. Se falamos aqui que Fidias levava em conta o ponto de vista, é justamente para afirmar que o que ele levava em conta é que a estátua seria apreciada em função das conexões que se estabeleceriam: as conexões que, neste caso, para Fidias, como para Stengers $(2008,2009,2012)$ antecedem aos termos. É, pois, o que se passa entre - no meso - o que faz existir a estátua e o seu observador. A dimensão meso-politica, intersticial, é para Stengers $(2012,2009)$ o plano das conexões, dos arranjos, da prática.

No livro 'Reflexão sobre o culto dos modernos deuses fe(i)tiches', Latour (2002) inicia contando a denúncia feita pelos portugueses acusando os africanos de bruxaria por acreditarem que um objeto tem poderes mágicos. "Enquanto o sábio aponta para a lua os tolos olham para o dedo (Latour, 2002, p. 80)." Dito isso, alerta para os perigos da denúncia crítica, pois ela separa atores que estão articulados. Caso se faça essa opção metodológica, inicialmente parece que não se perde nada, pois tanto os africanos quanto o objeto permanecem os mesmos, porém a denúncia crítica, aquela que opera pela purificação, faz perder de vista justamente o meso. Essa instância que se faz ver nas articulações, nos interstícios. É 
possível pensar que caminha nessa direção o alerta de Latour (2012, 2008, 1994,) para a importância de, ao fazer pesquisa, recusar a denúncia crítica. Mas por que?

Voltemos a história grega, o pedido feito por Fidias produziu um efeito, criou um espaço para o meso. Fez-ver isso que se põe no meio do lá-embaixo e do lá-em cima. Sim, pois a mesopolítica demanda um certo giro metodológico para se fazer presente. É nessa direção que Moraes (2010) cunha o PesquisarCOM. O COM é uma préposição, ela se anuncia como um ponto de partida para o trabalho de pesquisa, sem contudo informar o resultado. Ele também é uma próposição, pois aponta na direção de que os actantes sejam pensados em suas posições de fato e não deslocados a partir de uma denúncia crítica.

A denúncia crítica pode ser pensada também como uma estratégia metodológica. Quando os portugueses acusam os africanos de acreditarem em magia, eles emitem um julgamento. O perigo de um julgamento não reside somente no fato de poder estar certo ou errado, mas também no fato de que um julgamento encerra a questão. Quando as partes vão a juízo, cada uma delas apresenta seus argumentos, após isso cabe ao Juiz dar a sentença, emitir seu julgamento. Feito isso a questão se encerra, cabe às partes apenas executar aquilo que foi determinado pelo julgamento.

É nesse sentido que a denúncia crítica como estratégia metodológica nos impele ao fechamento e não à abertura. Antes que o julgamento sobre a mais bela estátua fosse dado, Fidias pede o meso, abre espaço para que ele faça seu trabalho, atue COM os juízes. O COM colocado não só ao lado, mas como princípio de um pesquisar recusa a denúncia crítica, porque pede que a questão permaneça aberta até que possa ser fechada não por um julgamento, mas por um arranjo trabalhado no âmbito da mesopolítica. Uma importante dimensão do fazerCOM outros a pesquisa é que se aposta na conexão, no que ela faz fazer a todos os envolvidos no dispositivo de pesquisa. FazerCOM implica, como salienta Stengers $(2009,2012)$, um processo de aprendizagem coletiva no qual todos hesitam juntos. Há no pesquisarCOM um investimento naquilo que no dispositivo de pesquisa produz equívoco, mal entendido, naquilo que brota como a grama de que falávamos - entre os tijolos do muro. O pesquisarCOM encontra ressonância com o que Donna Haraway (2008) sinaliza no tornar-se com: transformar-se no encontro com o outro, fazer proliferar um mundo mais denso, que não estava dado de antemão, um mundo inantecipável, tecido de elementos heterogêneos, díspares, humanos, não humanos, ciborgues.

Em nossa prática de pesquisa no campo da deficiência visual temos colocado em ação o fazerCOM, investindo em um modo de pesquisar situado (Viegas \& Tsallis, 2011; Moraes, 2010; Moraes \& Arendt, 2013). Parafraseando Donna Haraway (2008), perguntamos: no que 
tocamos quando pesquisamos no campo da deficiência visual? Se procedêssemos como na história de Fídias, talvez já tomássemos por suposto que a deficiência visual é algo sobre o quê já sabemos: define-se pela falta da visão ou por sua falha. No entanto, tal afirmativa é como aquela da qual Fidias queria se afastar, já que não se trata de tomar a deficiência visual como algo que se define isoladamente, cortando-lhe as conexões. Mas ao contrário, é nas conexões que a deficiência visual é tecida, do mesmo modo que a estátua de Palas Atena, para Fídias, só ganha sentido quando conectada a quem a olha, ao pedestal, ao centro do templo. As conexões performam a beleza de Palas Atena. No que tocamos quando pesquisamos no campo da deficiência visual? Tocamos em redes de conexões que articulam elementos heterogêneos, como relógios sonoros, bengala, o preconceito, os desafios de efetiva inclusão social, entre outros. O trabalho da pesquisa não é pinçar um destes elementos para investiga-lo isoladamente, mas ao contrário, é fazer proliferar as conexões, tornando o mundo mais denso, mas repleto de versões de eficiência e deficiência. É um trabalho de mesopolítica. Tornar-se com o outro, transformar-se, produzir mundos que se articulam, se compõem. É a ação do pesquisarCOM.

$\mathrm{Na}$ escrita destas linhas, uma cena de pesquisa insiste em se fazer presente. Era uma Oficina de Experimentação Corporal com pessoas cegas e com baixa visão, todos adultos, inscritos numa instituição de reabilitação para pessoas com deficiência visual. A Oficina era parte de uma pesquisa coordenada por um de nós e tinha como objetivo promover experimentações corporais a fim de sensibilizar o corpo, de conectá-lo a outros sentidos, a diversos materiais, fazendo-o diferir, mover-se. Na roda chega um participante, um homem com idade em torno de 30 anos e com baixa visão. Vinha com um caderno na mão. Dele não se largava. A todo momento nos convocava a escrever dados no seu caderno, dados que versavam sobre o horário das aulas, sobre as atividades a serem realizadas no dia seguinte. Como faríamos uma oficina de corpo com um caderno na roda? As atividades corporais propostas exigiam concentração ao som da música, às coordenadas dadas pelas pesquisadoras. O caderno, no entanto, insistia, se fazia presente com tenacidade. Hesitamos juntos: pesquisadores, participantes, caderno e corpos. No que tocamos quando pesquisamos no campo da deficiência visual? Tocamos num novelo emaranhado de conexões que performam eficiências e deficiências, fazendo combinações, composições inusitadas. Agregamos o homem-e-seu-caderno ao grupo, tornamos a Oficina mais densa, mais heterogênea. Negociamos com o cadernoe-seu-homem, e soubemos que o homem era analfabeto, as notas no caderno eram lidas sempre por sua mãe que, desse modo, acompanhava o seu dia a dia na reabilitação. Passamos a escrever no caderno também, não apenas as atividades do dia, mas também os 
retornos, as chamadas devoluções da pesquisa, o que pensávamos sobre nossos encontros. O caderno-na-roda abriu um mundo de afetos, de relações e de conexões. Trouxe-nos a mãe trabalhadora doméstica, trouxe-nos um mundo. Uma oficina de corpo-comcaderno, foi o que passamos a experimentar juntos. Cortar o caderno do homem seria retira-lo do grupo. Afinal, naquele grupo, ele nos disse uma vez, vocês não ficam também sempre a escrever alguma coisa num caderno? O diário de campo, era mais um caderno no grupo, não havíamos notado.

\section{Referências}

Arendt, R. J. J. (2008). Maneiras de pesquisar no cotidiano: contribuição da teoria do ator-rede. Psicologia e Sociedade, 20, 7-11.

Bellacasa, M. P. (2012) Politiques féministes et construction des savoirs. Penser nous devons. Paris: L'Harmant.

Despret, V. (1999). Ces émotions que nous fabriquent. Paris: Les Empêcheurs de Penser en Rond-Seuil.

Ferreira, A. A. L. (2011). La experiencia de subjetividad como condición y efecto de los saberes y prácticas psicológicas: producción de subjetividad y psicología. Estudios de Psicología (Ed. impressa), 32, 359-374.

Ferreira, A. A. L; Luna, L. F., Moraes, M., \& Arendt, R. (2010). Teoria Ator-rede e Psicologia. Rio de Janeiro: Nau.

Haraway, D. (2008). When species meet. USA: University of Minnesota Press.

Latour, B. (1994). Jamais fomos modernos. São Paulo: Editora 34.

Latour, B. (2002). Reflexão sobre o culto moderno dos deuses fe(i)tiches. São Paulo: EDUSC.

Latour, B. (2004). How to Talk About the Body? The Normative Dimension of Science Studies. Body \& Society, 10(2-3), 205229.

Latour, B. (2008). Reensamblar lo social. Una introducción a la teoría del actor-rede. Buenos Aires: Manantial.

Latour, B. (2012). Recherches sur les Modes d`existence. Une anthropologie des modernes. Paris: La Decouverte.

Law, J. (2004). After Method. Mess in social science research. New York: Routledge.

Mol, A. (2002). The Body Multiple: Ontology in Medical Practice. USA: Duke University Press.

Moraes, M. (2010). Política ontológica e deficiência visual. In M. Moraes, \& V. Kastrup (Orgs.). Exercícios de ver e não ver: arte e pesquisa com pessoas com deficiência visual (pp 26-51). Rio de Janeiro: Nau/Faperj. 
Moraes, M., \& Arendt, R. J. J. (2013). Guiar e ser guiado: ou do que é feita nossa (d)eficiência?. Universitas Humanistica, 76, 327347.

Stengers, I. (2012). Ecosophical activism - between micropolitics and mesopolitics A conversation on responsibility between Henk Oosterling and Isabelle Stengers. Recuperado em 1 de março, 2014, em http://www.svtuinen.nl/svt_files/Documents/ddrdamconversati onhois.pdf

Stengers, I. (2009). History through the Middle: Between Macro and Mesopolitics. Interview with Isabelle Stengers, 25 November 2008. Inflexions: A J ournal for Research-Creation, 3, 1-16.

Stengers, I. (2008). Experimenting with refrains: subjectivity and the challenge of escaping modern dualism. Subjectivity, 22, 38-59.

Stengers, I. (2006). La vierge et le neutrino. Les scientifiques dans la tourmente. Paris: Les empêcheurs de penser en rond.

Stengers, I. (2002a). Penser avec Whitehead. Paris: Le Seuil.

Stengers, I. (2002b). A invenção das ciências modernas. Rio de Janeiro: Editora 34.

Souriau, E. (2009). Les différents modes d'existence. Préface de Isabelle Stengers et Bruno Latour. Paris: Presse Universitaire Française.

Viégas, M. N., \& Tsallis, A. C. (2011). O encontro do pesquisador com seu campo: de janelas a versões. Pesquisas e Práticas Psicossociais, 6, 298-304.

\section{Endereço para correspondência \\ Ronald Arendt}

Universidade do Estado do Rio de Janeiro

Programa de Pós Graduação em Psicologia Social

Rua São Francisco Xavier, 524, 10 andar sala 10.009 bloco F, Maracanã, CEP 20550-900, Rio de Janeiro - RJ, Brasil

Endereço eletrônico: arendt.ronald@gmail.com

\section{Marcia Moraes}

Universidade Federal Fluminense

Programa de Pós Graduação em Psicologia - Campus do Gragoatá

Rua Prof. Marcos Waldemar de Freitas Reis, s/n, bloco O sala 214, Gragoatá, CEP 24210-201, Niterói - RJ, Brasil

Endereço eletrônico: marciamoraes@id.uff.br

\section{Alexandra Tsallis}

Universidade do Estado do Rio de Janeiro

Instituto de Psicologia

Rua São Francisco Xavier, 524, 10 andar sala 10.009 bloco F, Maracanã, CEP 20550-900, Rio de Janeiro - RJ, Brasil

Endereço eletrônico: atsallis@gmail.com

Recebido em: 24/07/2014

Reformulado em: 11/12/2014 
Aceito para publicação em: 15/12/2014

\section{Notas}

* Professor Titular da Universidade do Estado do Rio de Janeiro, Instituto de Psicologia, Departamento de Psicologia Social, Rio de Janeiro, Brasil. Doutor em Psicologia pelo Instituto Superior de Pesquisas Psicossociais da Fundação Getúlio Vargas - Rio de Janeiro (1987).

** Professora Associada do Departamento de Psicologia da Universidade Federal Fluminense, Niterói, Brasil. Doutora em Psicologia Clínica pela Pontifícia Universidade Católica de São Paulo (1998) Atua na Graduação e na Pós-graduação em Psicologia. Financiamento de pesquisa: Faperj, Cnpq, Capes.

*** Professora Adjunta do Departamento de Psicologia Social e Institucional do Instituto de Psicologia da Universidade do Estado do Rio de Janeiro, Rio de Janeiro, Brasil. Doutora em Psicologia Social pela UERJ em associação com a Ecole des Mines / Paris (2005). Atua na graduação e no Programa de Pós-graduação em Psicologia Social.

1 No texto referido Latour brinca com o slogan "INTEL Inside" utilizado pela empresa de processadores eletrônicos INTEL em suas propagandas.

2 O termo utilizado pela autora é assemblage. Law (2004) adverte que a palavra assemblage, em inglês foi muitas vezes traduzida de agencement, em francês. Segundo o autor, a palavra francesa guarda o sentido de um verbo, uma ação de conectar, ligar, agenciar. Em inglês, assemblage é um substantivo que pode ser traduzido para o português como um agregado, uma juntada. No entanto, a dimensão do verbo, isto é, a ação de agenciar, conectar fica obscurecida com este termo em inglês. No presente ensaio traduzimos a palavra assemblage por agenciamento justamente para preservar a dimensão do verbo, da ação.

3 A performatividade aqui guarda relação com o termo enact, usado também por Mol (2002) para dizer que nenhum objeto existe sem estar articulado às práticas que o produzem e o fazem existir. Em inglês enact aponta para dois sentidos distintos: como encenar, representar um papel; e como fazer existir, promulgar, fazer, no sentido, por exemplo quando dizemos que "o congresso nacional promulgou (fez existir) uma nova lei" (Ver: http://dictionary.reference.com/browse/enact). Nas palavras da filósofa: "É possível dizer que nas práticas os objetos são feitos [enacted] (...) isto sugere também que em ato, e apenas aqui e acolá, alguma coisa é - sendo feita [being enacted]" (Mol, 2002, p32-33). Neste artigo, retomamos o sentido proposto por Mol (2002) com o verbo enact.

${ }^{4}$ Fazer fazer é uma expressão utilizada por Latour $(2008,2002)$ para dar conta do deslocamento da ação que marca o ator-rede. Parafraseando as palavras do autor, dizemos que a ação é um nó, um conglomerado de muitos conjuntos de agências. A ação é antes uma fonte de incerteza do que de certeza. O fazer fazer indica o caráter distribuído das fontes de ação.

${ }^{5}$ Ao leitor interessado, recomendamos vivamente a leitura da introdução aos textos de Souriau escrita por Stengers e Latour. Cf. Souriau, 2009.

6 Encaminhamos um leitor interessado ao ensaio que Stengers redigiu sobre o filósofo (Stengers, 2002b). 